\title{
KEWAN PITIK (APLIKASI PEMANTAUAN, KONTROL DAN KEAMANAN KANDANG AYAM DENGAN GOOGLE FIREBASEBERBASIS INTERNET OF THINGS)
}

\author{
Muhammad Ikhwan Fathulloh ${ }^{1}$, Ahsani Takwim ${ }^{2}$, Dimas Aji Permadi ${ }^{3}$, Shalih Rizaldy ${ }^{4}$ \\ Program Studi Teknik Informatika, Sekolah Tinggi Teknologi Bandung ${ }^{1,2,3,4}$ \\ muhammadikhwanfathulloh17@gmail.com¹, ahsanitakwim@sttbandung.ac.id ${ }^{2}$, dajip569@gmail.com³, \\ shalihrizal@gmail.com ${ }^{4}$
}

\section{Abstrak}

Prioritas permasalahan yang dihadapi oleh UKM peternakan ayam saat ini terletak pada tata cara perawatan ayam selama beternak. Mayoritas pemberian pakan untuk ayam masih dilakukan secara manual, serta kesulitan dalam hal pengaturan suhu dalam kandang yang menyebabkan tingkat kematian ayam cukup tinggi yaitu mencapai 8\% dari 1000 ekor ayam mati tiap kali ternak (35 hari). Tentunya hal ini, akan mempengaruhi pendapatan yang diperoleh UKM peternakan ayam. Tujuan dari penelitian ini adalah untuk membantu memberikan solusi terhadap permasalahan UKM peternakan ayam sehingga diharapkan dapat meningkatkan produktivitas UKMdalam upaya memenuhi kebutuhan pasar akan daging ayam. Sistem ini dapat digunakan untuk memberi pakan dan mengatur suhu secara otomatis yang dapat dikontrol dan dimonitor dari jarak jauh melalui aplikasi android dan aplikasi website dengan memanfaatkan jaringan internet.

Kata kunci : Internet of Things, Kandang Ayam, Aplikasi Android, Aplikasi Website.

\begin{abstract}
The priority problems faced by chicken farming SMEs currently lie in the procedures for caring for chickens while raising chickens. The majority of feeding for chickens is still done manually, as well as difficulties in regulating the temperature in the cage which causes the death rate of chickens to be quite high, reaching $8 \%$ of 1000 chickens die every time the livestock (35 days). Of course, this will affect the income earned by chicken farming SMEs. The purpose of this study is to help provide solutions to the problems of chicken farming SMEs so that it is expected to increase the productivity of SMEs in an effort to meet market needs for chicken meat. This system can be used to feed and regulate the temperature automatically which can be controlled and monitored remotely through android applications and website applications by utilizing the internet network.

Keywords : Internet of Thing, Chicken Coop, Android Application, Website Application.
\end{abstract}

\section{PENDAHULUAN}

Ayam merupakan komoditas hasil peternakan yang banyak dibudidayakan di Indonesia. Selain itu, ayam merupakan hasil peternakan yang berpotensi tinggi untuk diperjual belikan. Ayam juga menjadi bahan pangan yang digemari dan paling dibutuhkan oleh setiap orang[8]. Buktinya, banyak usaha seperti restoran hingga warung makan yang menyajikan santapan menu dengan bahan utama ayam. Tidak heran, saat ini bisnis ternak ayam di Indonesia kian menjamur. Namun dengan demikian, tata cara perawatan selama beternak juga perludikembangkan agar dapat meningkatkan mutu ternak.

Data Badan Pusat Statistik (BPS) Indonesia tahun 2020 menunjukkan bahwa jumlah populasi ayam pedaging di seluruh provinsi Indonesia mencapai angka 2.970.493.660 dengan populasi terbanyak berturut-turut terdapat di Provinsi Jawa Barat, Jawa Tengah dan Jawa Timur. Tingginya populasi ternak dapat mengidentifikasi bahwa jumlah peternak di Indonesia cukup tinggi [5].

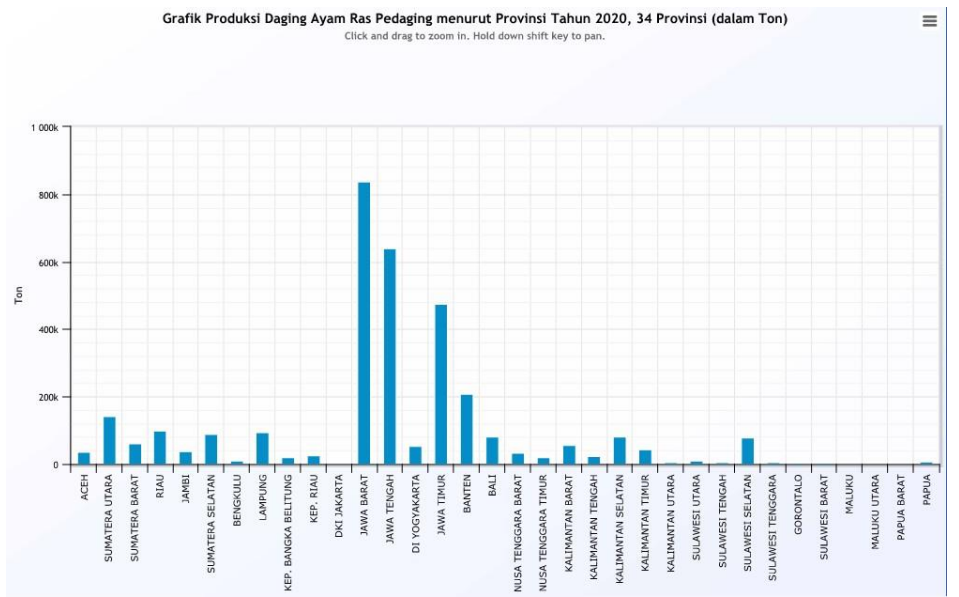

Gambar 1 Grafik Produksi Daging Ayam Ras Pedaging menurut Provinsi Tahun 2020, 34 Provinsi (dalam Ton)

Sumber: Direktorat Jenderal Peternakan dan Kesehatan Hewan, Kementan Data 2020 adalah data sementara

Proses perawatan ayam pada umumnya meliputi pemberian pakan dan suplemen tambahan, pengaturan suhu kandang, hingga pemantauan secara berkala terhadap pertumbuhan dan perkembangan ayam. Ayam mulai diternak sejak kecil hingga usia ayam 2,5 - 3 bulan. Tetapi, apabila berat ayam perekor sudah mencapai target, ayam akan dipanen. Dalam proses peningkatan sektor peternakan, khususnya peternakan skala kecil hingga menengah masih 
ditemukan kendala pengembangan sistem peternakan ayam yang berbasis agribisnis dan agroindustri, diantaranya lemahnya struktur dan akses permodalan, seperti sistem peminjaman modal saat memulai usaha ternak dengan perjanjian pembayaran setelah panen yang secara ekonomi akan merugikan pihak peternak, dan terbatasnya keahlian dalam penguasaan teknologi[7]. Mayoritas peternakan ayam di Indonesia, baik ayam pedaging maupun petelur masih menggunakan metode (manual/konvensional) dalam proses perawatan ayam. Tentunya hal ini tidak efisien dari segi waktu, tenaga, dan biaya. Sebagai contoh, apabila letak kandang ayam dan rumah pemilik yang jauh mengakibatkan pemilik harus pulang pergi dari rumah ke kandang untuk melakukan perawatan terhadap ayam nya. Maraknya pencurian ayam juga membuat peternak mengalami kerugian dan tidak dapat memproduksi sesuai yang diharapkan, disebabkan keamanan kandang yang mudah dibobol oleh pelaku pencurian.

KEWAN PITIK merupakan teknologi yang dapat melakukan pemantauan suhu dan kelembapan kandang ayam. Sehingga bisa menjaga kondisi kandang sesuai dengan karakteristik suhu ayam secara realtime. Melakukan kontrol pemberian pakan ayam dengan conveyor dan mengecek kuantitas isi pakan, serta sistem keamanan kandang dengan RFID dengan kartu dan id kartu untuk dapat mengakses kandang ayam dan aplikasi android KEWAN PITIK. Memantau perkembangan peternakan ayam dengan aplikasi website KEWAN PITIK. Kontrol pemberian pakan secara otomatis melalui conveyor, serta pemantauan kuantitas pakan didalam tabung dengan aplikasi. Menjaga suhu dan kelemabapan kandang sesuai kenyaman ayam, jika suhu panas kipas sentrifugal akan menyerap udara panas, serta saat suhu dingin lampu akan menyala untuk menghangatkan kandang.

\section{TINJAUAN PUSTAKA}

\section{Peternakan Ayam}

Peternakan ayam adalah salah satu andalan dalam salah satu usaha bisnis di Indonesia. Peternakan ayam khususnya ayam pedaging mempunyai prospek yang sangat baik untuk dikembangkan, baik dalam skala besar maupun skala kecil. Pembangunan peternakan ayam ras pedaging di Indonesia dapat dilihat dari perkembangan populasinya[5]

\section{Wemos D1 R1 ESP8266}

Wemos D1 R1 merupakan board yang dikembangkan berdasarkan ESP 8266 yang merupakan IC komunikasi Wi-Fi yang dirancang menyerupai Arduino Uno, namun dari sisi spesifikasi, sebenarnya jauh lebihunggul Wemos D1 R1, salah satunya dikarenakan inti dari Wemos D1 R1 adalah ESP8266EX yang memiliki prosesor 32 bit. Dimana, ESP8266 tidak hanya berfungsi sebagai hosting aplikasi namun dapat juga berfungsi sebagai offloading semua jaringan internet processor aplikasi lain [4].

\section{RFID-RC522}

Mifare RC522 adalah sebuah modul berbasis IC Philips MFRC522 yang dapat membaca RFID dengan penggunaan yang mudah dan harga yang murah, karena modul ini sudah berisi komponen-komponen yang diperlukan oleh MFRC522 untuk dapat bekerja [6]

4. LCD Display $16 \times 2$

LCD (Liquid Crystal Display) adalah suatu jenis media tampil yang menggunakan kristal cair sebagai penampil utama.

\section{DHT 11}

Sensor SHT11 merupakan suatu sensor jenis digital yang biasanya dimanfaatkan untuk mengukur kelembapan dan suhu relatif yang dilengkapi dengan multi modul sensor yang outputnya dikalibrasi secara digital. Sensor ini terhubung secara internal melalui konventer analog digital 14 bit dengan membuat sebuah sinyal keluaran yang baik dan waktu respon yang cepat [1].

\section{Ultrasonic HC-SR04}

Sensor ultrasonik adalah suatu sensor yang mekanisme kerjanya menggunakan pantulan bunyi, dimana bunyi tersebut akan diubah menjadi besaran listrik dengan memancarkan gelombang ultrasonik yang berasal dari benda piezoelektrik dengan besaran gelombang ultrasonik yang dihasilkan sebesar $40 \mathrm{kHz}$ (Aktanto, 2016). Sensor ultrasonik yang digunakan kali ini yakni sensor ultrasonik HCSRF-04. Sensor ultrasonik HCSRF-04 dapat mengukur jarak dengan rentang $3 \mathrm{~cm}-3 \mathrm{~m}$.

\section{Servo Motor}

Servo motor adalah servo mekanisme loop tertutup yang menggunakan umpan balik posisi untuk mengontrol gerakan dan posisi akhirnya. Input ke kontrolnya adalah sinyal yang mewakili posisi yang diperintahkan untuk poros output. 
8. Relay

Relay adalah suatu peranti yang menggunakan elektromagnet untuk mengoperasikan seperangkat kontak sakelar. Susunan paling sederhana terdiri dari kumparan kawat penghantar yang dililit pada inti besi.

\section{Lampu}

Lampu adalah sebuah peranti yang menghasilkan cahaya. Kata "lampu" dapat juga berarti bola lampu. Lampu pertama kali ditemukan oleh Sir Joseph William Swan.

10. Blower

Kipas sentrifugal adalah alat mekanis untuk menggerakkan udara atau gas lain ke arah yang bersudut dengan fluida yang masuk.

11. Aplikasi Android

Aplikasi android menjadi salah satu platform yang saat ini digemari oleh setiap developer dalam mengembangkan perangkat lunak berbasis mobile.

12. Aplikasi Website

Aplikasi website adalah suatu aplikasi yang diakses menggunakan penjelajah web melalui suatu jaringan seperti Internet atau intranet.

\section{Internet of Things}

Internet untuk Segala-(nya) (bahasa Inggris: Internet of Things, atau dikenal juga dengan singkatan IoT) merupakan sebuah konsep yang bertujuan untuk memperluas manfaat dari konektivitas internet yang tersambung secara terus-menerus.

\section{Google Firebase}

Firebase adalah suatu layanan dari Google yang digunakan untuk mempermudah para pengembang aplikasi dalam mengembangkan aplikasi. Dengan adanya Firebase, pengembang aplikasi bisa fokus mengembangkan aplikasi tanpa harus memberikan usaha yang besar [3].

\section{ANALISIS DAN PERANCANGAN}

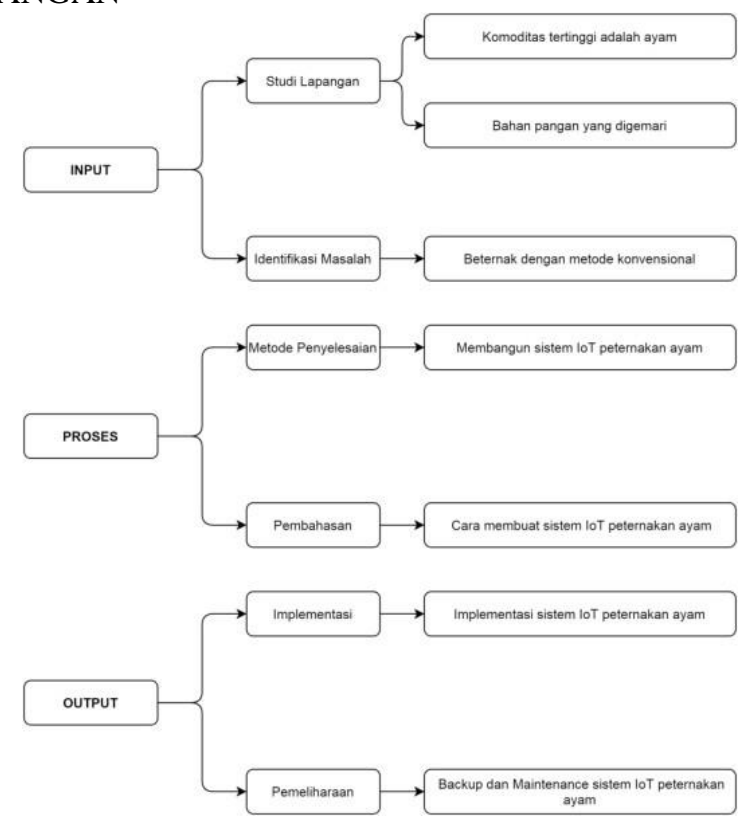

Gambar 2 Analisa dan Perancangan Kewan Pitik

(Sumber: Dokumen Pribadi, 2021)

1. INPUT

a. Studi Lapangan; Menganalisa komoditas tertinggi di indonesia berdasarkan data BPS (Badan Pusat Statistika)dan menjadi bahan pangan yang paling digemari oleh masyarakat di indonesia.

b. Identifikasi Masalah; Beternak ayam masih dengan metode konvensional/manual dari segi pemantauan, kontroldan keamanan kandang ayam.

\section{PROSES}

a. Metode Penyelesaian; Membangun sistem Internet of Things Peternakan Ayam untuk melakukan 
pemantauan,kontrol dan keamanan kandang secara realtime.

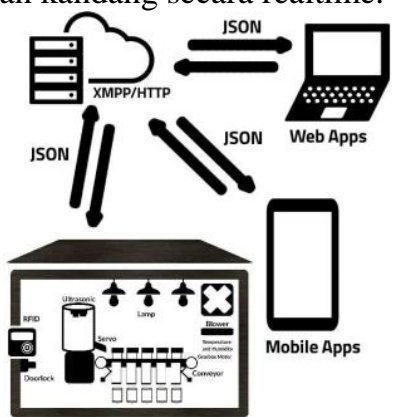

Gambar 3 Sistem komunikasi data antar perangkat (Sumber: Dokumen Pribadi, 2021)

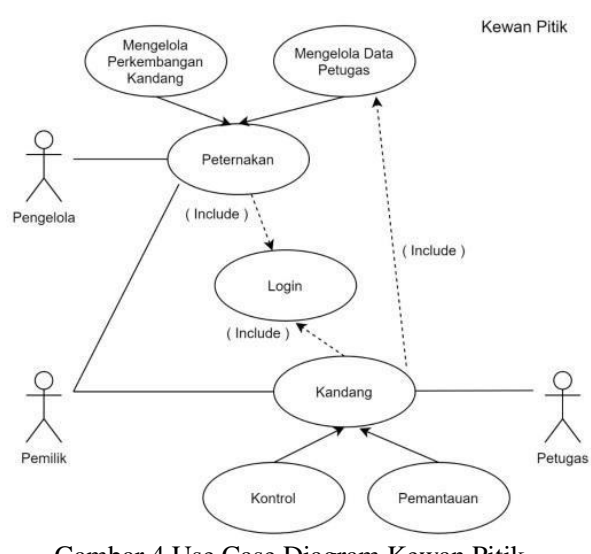

Gambar 4 Use Case Diagram Kewan Pitik (Sumber: Dokumen Pribadi, 2021)

Sistem bekerja dengan 3 hak akses user yakni pemilik untuk akses aplikasi website dan android, pengelola memiliki akses ke aplikasi website dan petugas akses ke aplikasi android.

1. Aplikasi Website

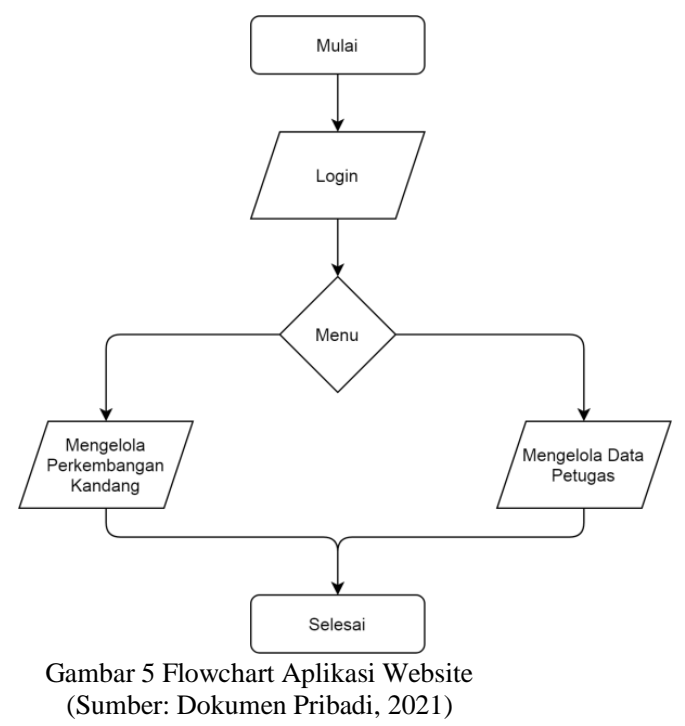

Berfungsi untuk mendaftarkan kartu petugas/user ke Google Firebase agar dapat mengakses kandang, serta UID dari kartu berguna untuk login ke Aplikasi Android berfungsiuntuk melakukan pemantauan dan kontrol kandang ayam. Dan memantau perkembangan kandang ayam secara berkala, serta melakukan evaluasi dari setiap kondisi kandang agar dapat terus meningkatkan kualitas produksi. 
2. Aplikasi Android

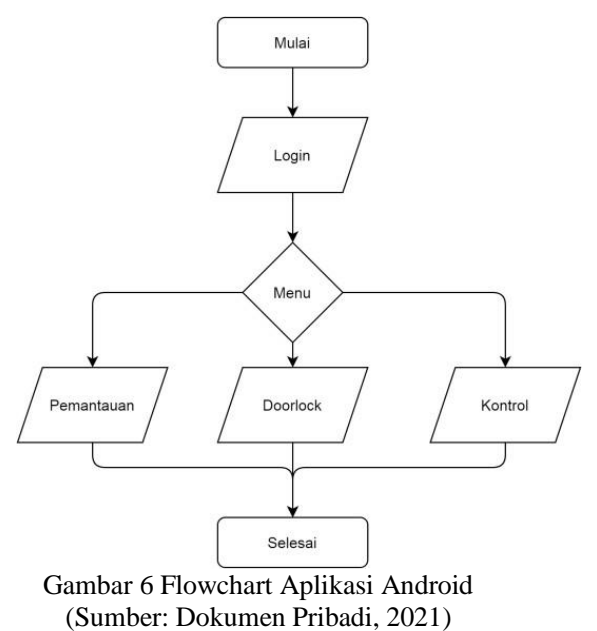

Hanya dapat diakses oleh petugas/user yang kartunya telah terdaftar, jika sudah maka akan mendapat UID dari kartu untuk login ke aplikasi dengan mengambil data di Google Firebase. Di aplikasi petugas/user dapat melakukan pemantauan dan kontrol kandangayam dengan smartphone, serta jika petugas/user lupa membawa kartu hanya dengan mengingat UID dan login ke aplikasi akses kandang dapat dibuka.

\section{RFID Doorlock}

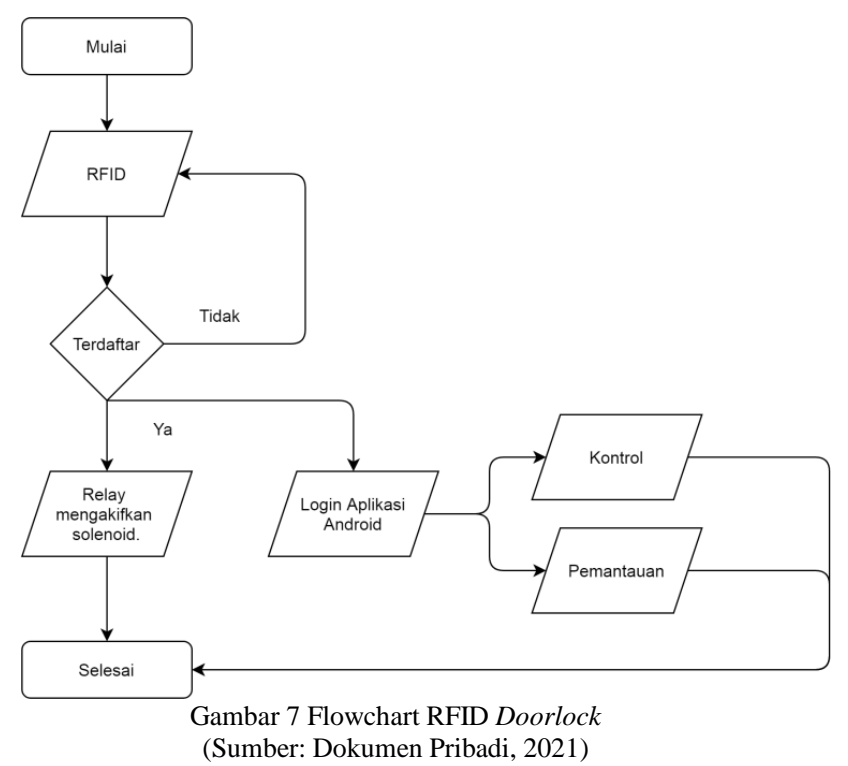

Berfungsi untuk mengakses dan memverifikasi data petugas/user yang sudah terdaftar ke Google Firebase, jika terdaftar maka solenoid doorlock akan terbuka. Digunakanuntuk mendaftar dan mengubah kartu petugas/user. 
4. Kontrol Pakan

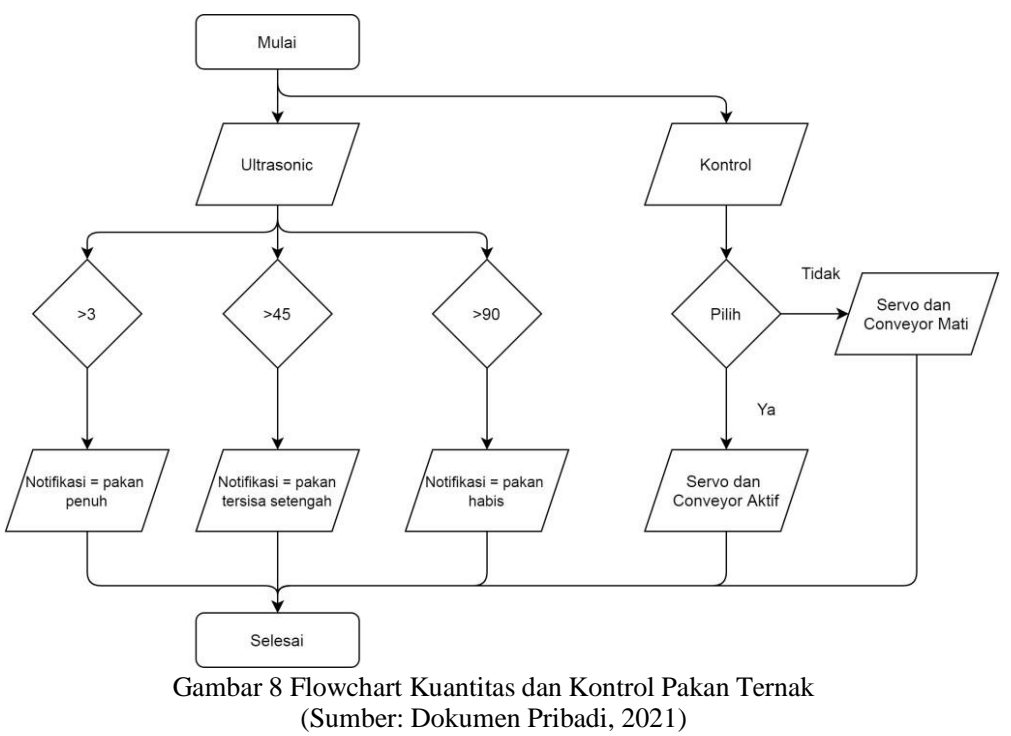

Berfungsi untuk pemberian pakan secara otomatis. Pakan disimpan didalam tabung yang besarnya sesuai kebutuhan peternak, dan dapat dipantau kuantitas isinya melalui aplikasi android dan website. Pemberian pakan dilakukan menggunakan conveyor dan dipilah dengan palang ke tempat pakan ayam.

5. Deteksi Suhu dan Kelembapan

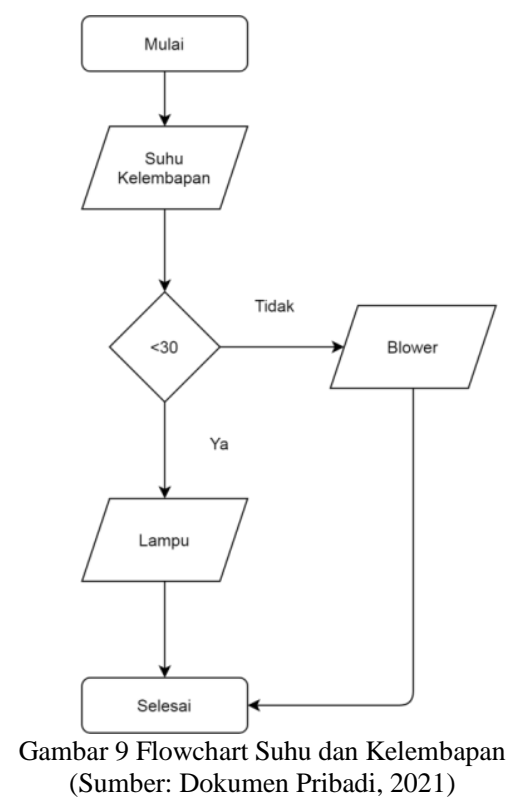

Berfungsi untuk menjaga kondisi kandang agar selalu sesuai dengan suhu kenyamanan ayam. Jika suhu panas maka sistem akan menyalakan blower untuk menyerap suhu panas keluar, sedangkan jika suhu dingin maka lampu akan menyala untuk menghangatkan kandang. Serta dapat pula dikontrol secara manual dengan aplikasi android maupun website. 
6. Rancangan Embedded System

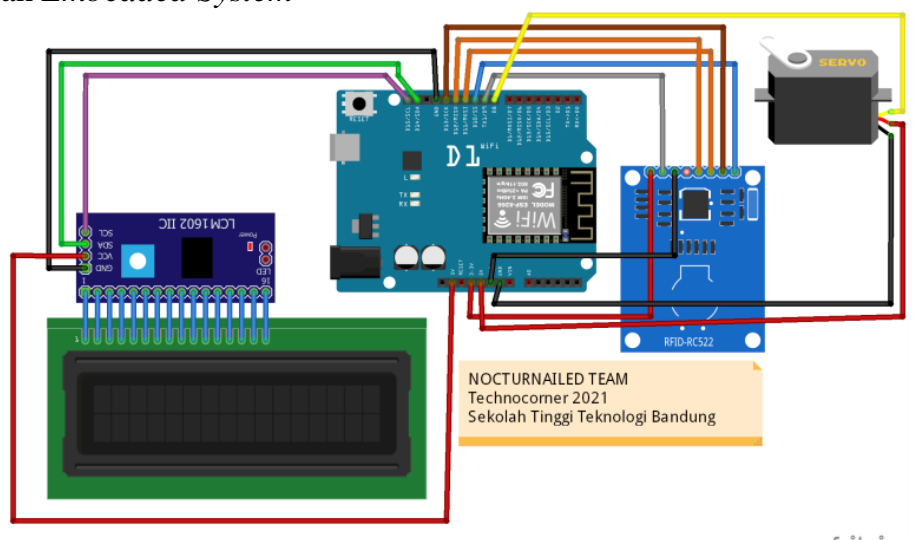

Gambar 10 Desain Perangkat Keamanan

fritzing

(Sumber: Dokumen Pribadi, 2021)

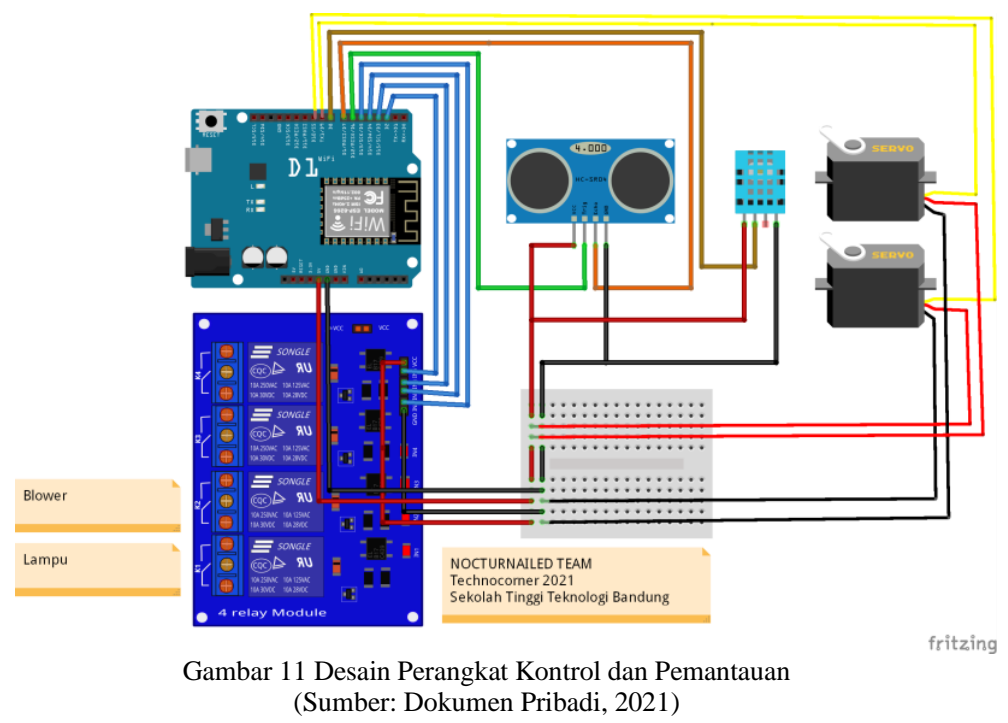

7. Rancangan Aplikasi Android

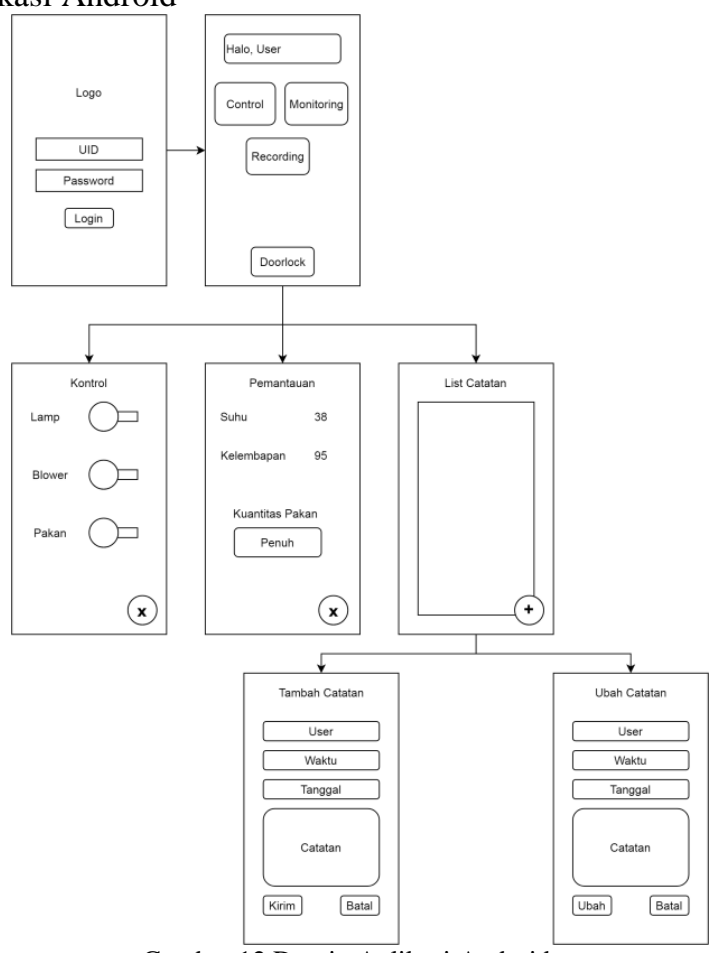

Gambar 12 Desain Aplikasi Android

(Sumber: Dokumen Pribadi, 2021) 
8. Rancangan Aplikasi Website

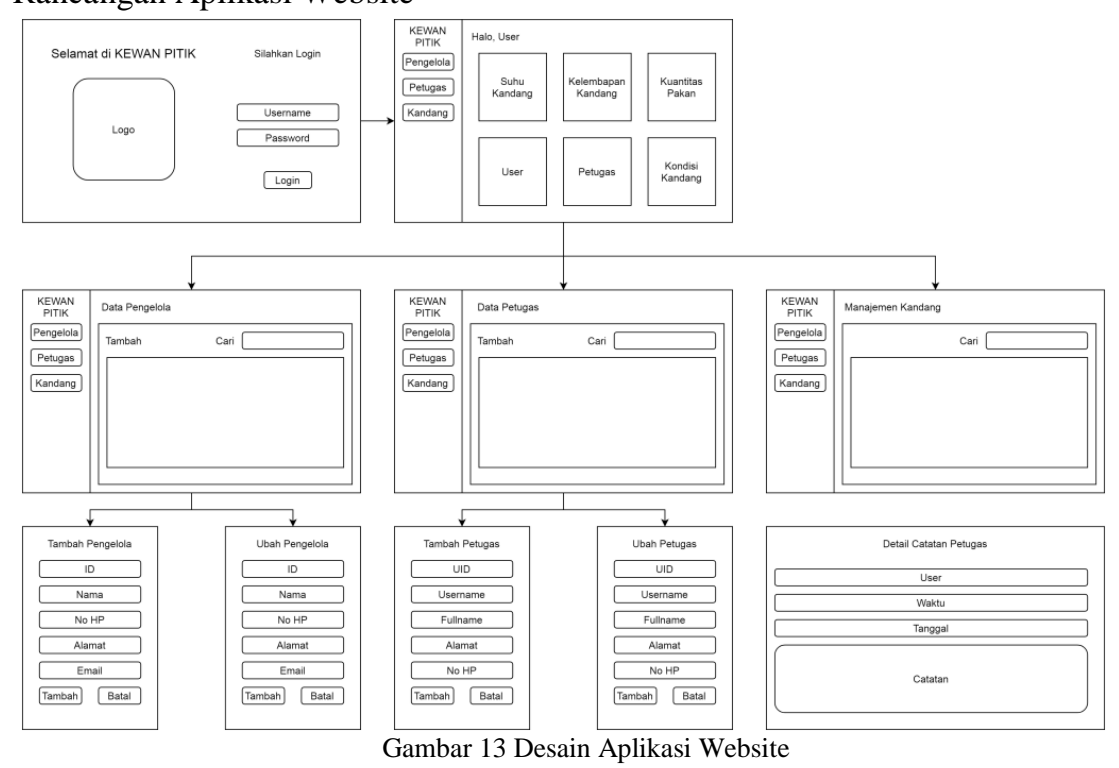

(Sumber: Dokumen Pribadi, 2021)

b. Pembahasan; Cara Membuat sistem Internet of Things Peternakan Ayam untuk melakukan pemantauan, kontrol dan keamanan kandang secara realtime dengan Google Firebase.

1. Embedded System
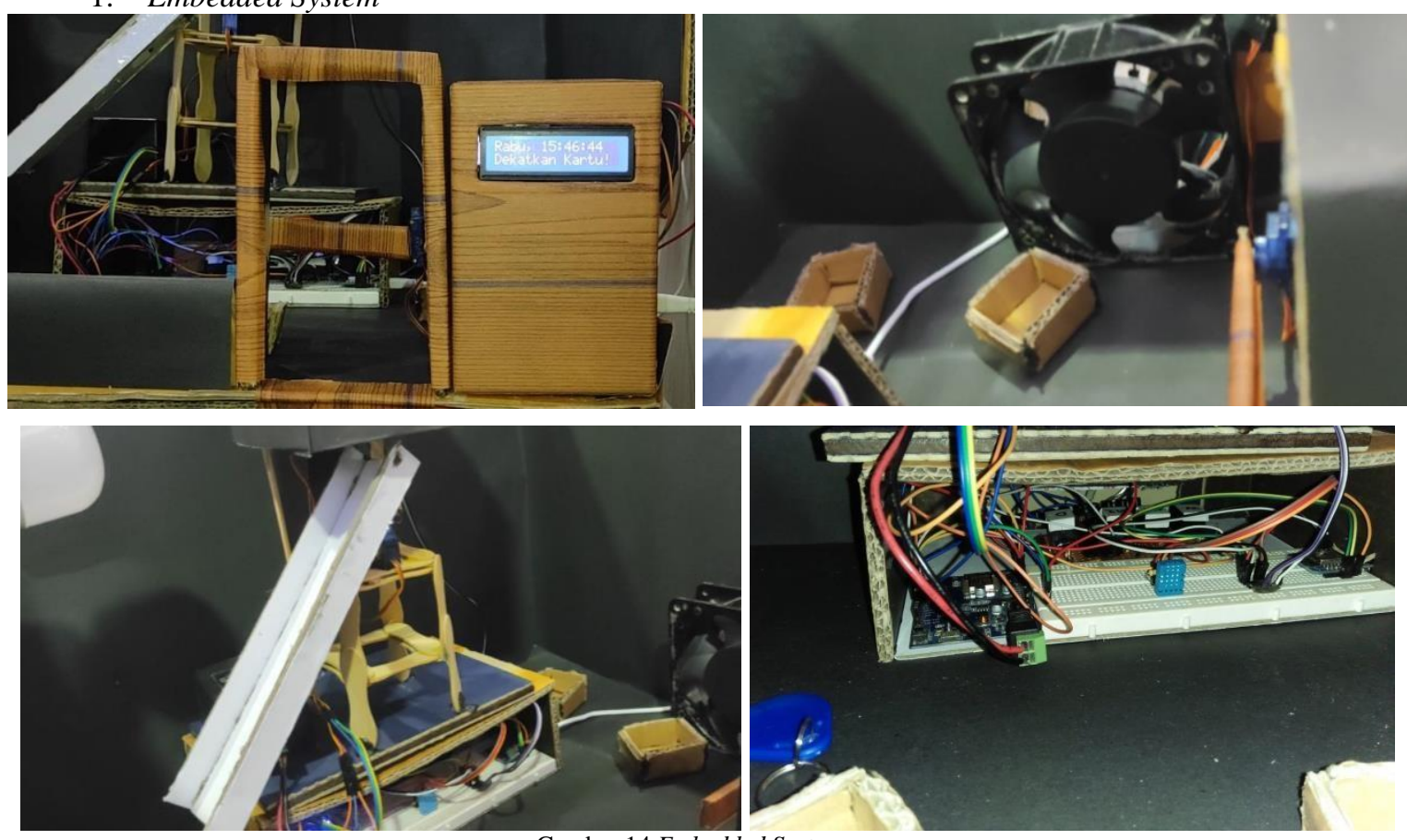

Gambar 14 Embedded System

(Sumber: Dokumen Pribadi, 2021) 
2. Aplikasi Android

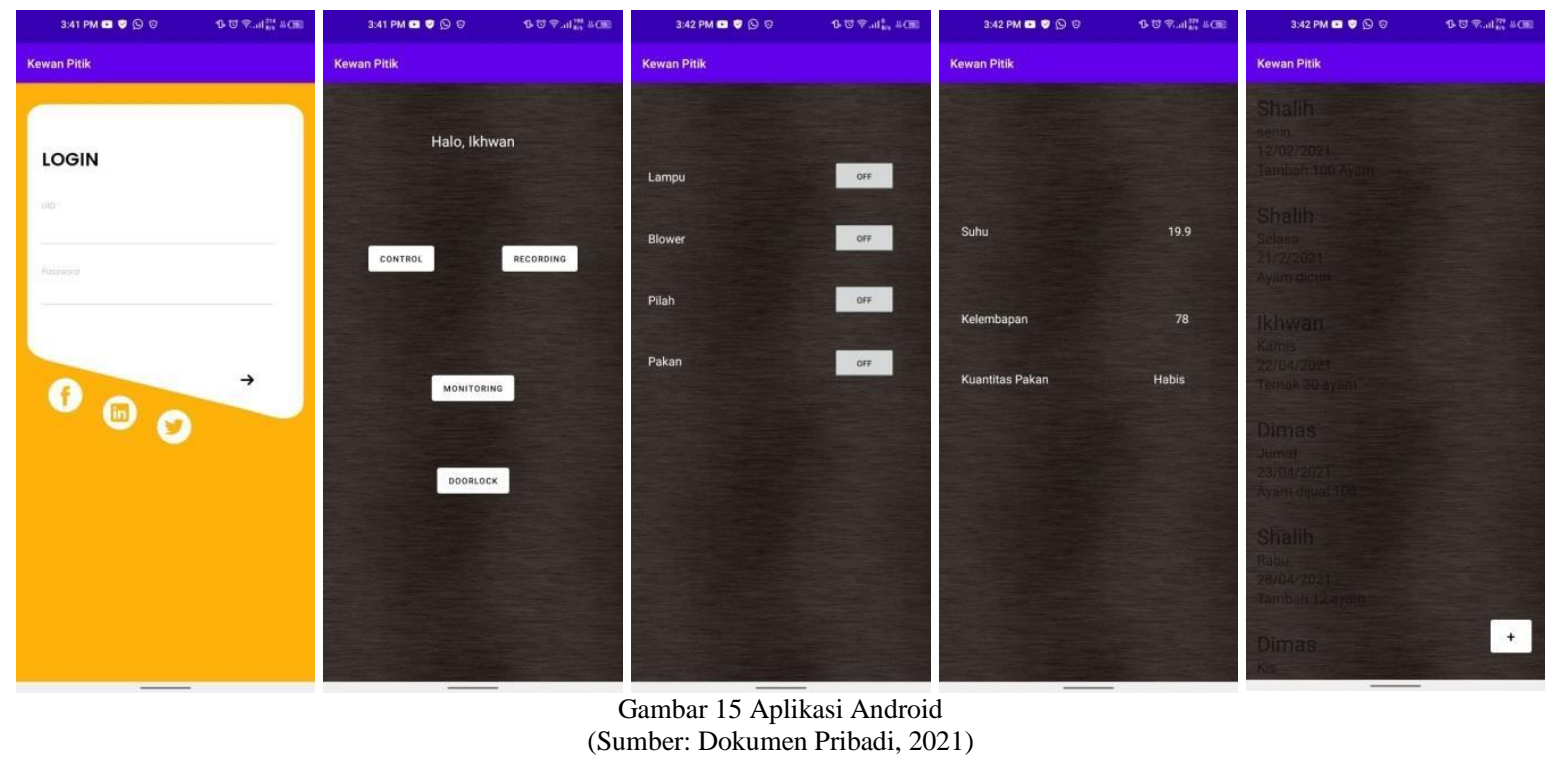

3. Aplikasi Website
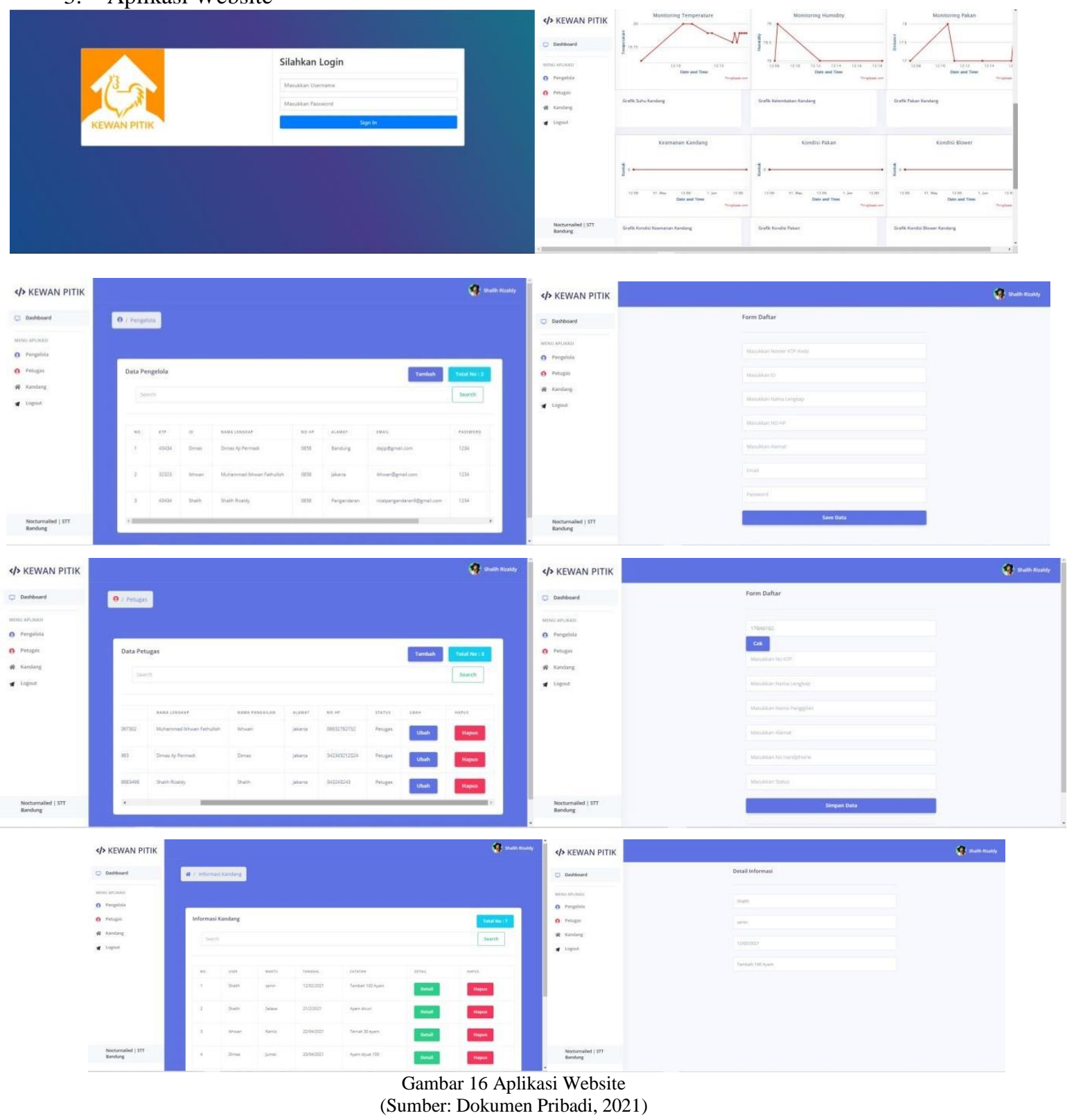


\section{OUTPUT}

a. Implementasi; Implementasi sistem Internet of Things Peternakan Ayam meliputi pemantauan, kontrol dan keamanan kandang secara realtime. Adapun video prototype yang telah dibuat untuk menjelaskan sistem secara keseluruhan dan telah diunggah pada link berikut https://s.id/VideoKewanPitik

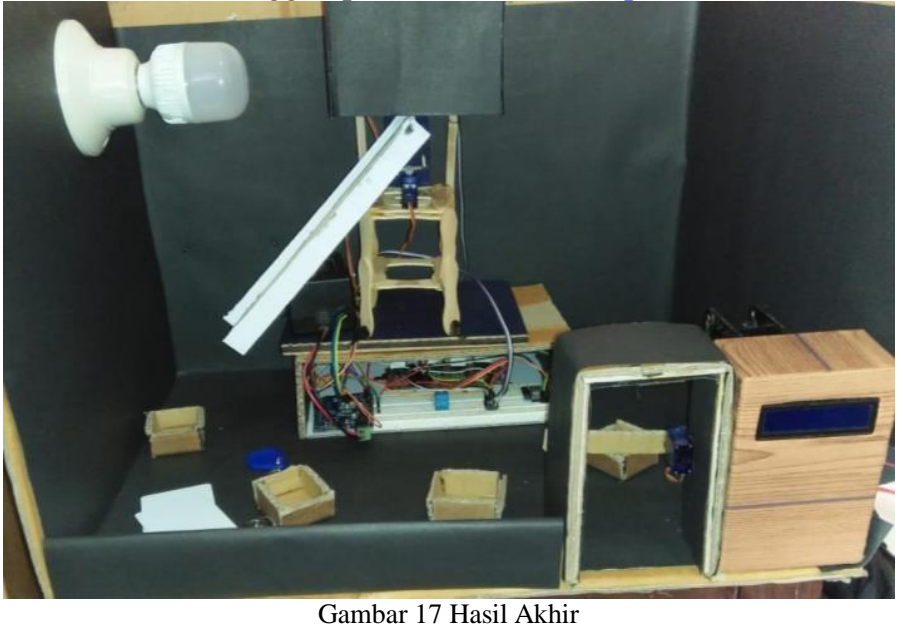

(Sumber: Dokumen Pribadi, 2021)

b. Pemeliharaan; Backup dan Maintenance sistem Internet of Things Peternakan Ayam meliputi pemantauan, kontrol dan keamanan kandang secara realtime.

\section{KESIMPULAN}

Dari permasalahan peternakan di indonesia salah satunya pada lingkup ternak ayam yang menjadi komoditas konsumsi tertinggi. Serta kendala yang dialami peternak ayam, dimana sistem beternak masih menggunakan cara manual, mulai dari pemberian pakan dengan cara petugas berkeliling kandang, melakukan pengecekan suhu tidak bisa secara berkala karena harus berada dikandang, dan Keamanan kandang yang masih bisadibobol oleh pelaku pencurian.

Dengan KEWAN PITIK yang berusaha menjawab semua permasalahan tersebut dengan sistem keamanan kandang sistem doorlock RFID, kontrol pemberian pakan secara otomatis dengan conveyor dan memantau kuantitas pakan didalam tabung, serta pemantauan suhu dan kelembapan kandang secara realtime untuk menyesuaikan suhu kandang dengan kenyamanan sesuai karakteristik ayam. Diharapkan mampu meningkatkan produktivitas peternak ayam dalam mengembangkan usahanya dan membantu permasalahan yang sering dialami oleh para peternak ayam di seluruh indonesia.

\section{REFERENSI}

[1] Agusta, A.R., et all 2019, Implementasi Internet of Things untuk Menjaga Kelembapan Udara pada Budidaya Jamur, Jurnal Fakultas Teknlogi Industri Universitas Kristen Petra.

[2] Aktanto, Mujtahid 2016, 'Multi Ultrasonic Travel Aids (MU-ETA) sebagai Alat Bantu Penunjuk Jalan Bagi Tuna Netra',Jurnal Biosains Pasca Sarjana UNAIR, vol. 18, no. 2, pp. 150-165.

[3] Hartawan, I. N. B. \& Sudiarsa, I. W., 2019. Analisis Kinerja Internet of Things Berbasis Firebase Real-Time Database. Resistor, 1(1), pp. 6-14.

[4] Nugroho, A. Ridzo 2017, 'Security System pada Kendaraan Bermotor dengan Software Management yang Terhubung dengan Konsep IoT Bebasis Nodemcu ESP8266 pada PT. Gemilang Motor',Jurnal Skripsi STMIK Raharja.

[5] Peternakan, S. S., 2020. Peternakan Dalam Angka 2020. 2714-8416 ed. Jakarta: BPS-RI/BPS-Statistic Indonesia.

[6] Susanto, R., Ananta, A., Santoso, A. \& Trianto, M., 2009. Sistem Absensi Berbasis RFID. Teknik Komputer, 17(1), pp. 67-74.

[7] Sutomo, Edy 2016, 99\% Gagal Beternak Ayam Broiler, Penebar Swadaya, Jakarta.

[8] Winda, Aprianda, et all 2016, Pola Konsumsi Daging Ayam Broiler Berdasarkan Tingkat Pengetahuan dan Pendapatan Kelompok Mahasiswa Fakultas Peternakan Universitas Padjadjaran, Jurnal Fakultas Peternakan Universitas Padjajaran, pp. 1-16. 